\title{
Side effect experiences of South Korean women in their twenties and thirties after facial plastic
} surgery

\author{
Young A Kim' \\ Hyang-In Cho Chung ${ }^{2}$ \\ 'Department of Nursing, Jeju National \\ University College of Nursing, Jeju-si, \\ Republic of Korea; ${ }^{2}$ Department \\ of Nursing, Chonnam National \\ University College of Nursing, \\ Gwangju, Republic of Korea
}

This article was published in the following Dove Press journal: International Journal of Women's Health

Background: Rates of plastic surgery procedures have increased dramatically over the past several decades, especially for the women in South Korea.

Purpose: The purpose of this study was to explore the subjective experience of South Korean women in their twenties and thirties with facial plastic surgery (FPS) side effects.

Participants and methods: Seven women who have suffered from FPS side effects participated in this study. Data were collected from July to September 2015 through individual in-depth interviews using open-ended questions and analyzed using Colaizzi's method, which is a Husserlian phenomenological approach.

Results: Six themes, and 25 subthemes, were found. Major themes were "choosing FPS to gain a new self", "facing an unintended self", "trying to accept a changed self", "making efforts to overcome the situation", "coming to know a new world", and "pursuing a new lifestyle".

Conclusion: This study raises social awareness on the risk of plastic surgery side effects, which could prevent unnecessary plastic surgery. It also suggests the need for a deeper understanding of women's biopsychosocial suffering from plastic surgery side effects.

Keywords: cosmetic surgery, aesthetic plastic surgery, qualitative research, interview

\section{Introduction}

Plastic surgery has become increasingly popular in South Korean society with advancements in medical technologies and the sociocultural climate embracing these types of procedures. According to the International Society of Aesthetic Plastic Surgery (ISAPS), ${ }^{1}$ incidences of surgical and nonsurgical cosmetic procedures reached 13.1 cases per 1,000 Koreans, which is indisputably the highest in the world. In fact, a random survey of Korean female college students showed that $45.7 \%$ of the respondents had an experience with a surgical or nonsurgical aesthetic procedure. ${ }^{2}$ The Seoul Urban Policy Index Analysis also confirmed that the proportion of respondents claiming that they "could undergo plastic surgery to enhance appearances" was on the rise from $21.5 \%$ in 2007 to $36.4 \%$ in $2013 .^{3}$

Plastic surgery provides a direct method of reconstructing the body based on specific perspectives such as youth or femininity, but such attempts of resizing and reshaping the body is undoubtedly accompanied by surgery failures or side effects. ${ }^{46}$ According to the Korea Consumer Agency, ${ }^{7}$ there were 110 cases in 2013 and 104 cases in 2014 of plastic surgery-related complaints reported, $68.7 \%$ of which were cases of "postoperative side effects". More than half of the side effects occurred after facial plastic surgery (FPS) including that of the eyes and nose with $88.4 \%$ of these cases having
Correspondence: Hyang-In Cho Chung Department of Nursing, Chonnam National University, I 60 Baekseo-ro, Gongogu, Gwangju 6I469, Republic of Korea

Tel +82 625304934

Fax +82 622204544

Email hchoch@hanmail.net 
already undergone or were in need of reoperation. Types of side effects included asymmetry, scarring, skin sensitization, discoloration, displacement of implants, muscular dysfunction or impairment, keratosis, edema, oozing, and flexion. ${ }^{2,8,9}$ In addition, the fear of potential side effects has been shown to induce severe anxiety in victims. ${ }^{10}$

Despite these side effects, however, there are no official data that can identify the current status of cosmetic surgeries, as well as their complications and side effects in Korea, primarily due to cosmetic procedures in Korea not being covered by health insurance. ${ }^{8}$ This lack of data revealing the pain of individuals suffering from cosmetic surgery side effects hinders the provision of appropriate nursing intervention or the development of policies.

People in their twenties and thirties are the demographic that most frequently seeks and receives FPS in Korea. They account for $60.8 \%$ of the side effect cases, $80.8 \%$ of which belong to women. ${ }^{7}$ These statistics call for an in-depth understanding of the experiences of this age group. In other words, there is a need to understand the method of controlling and coping with psychosocial reactions and symptoms utilized within this population.

Notwithstanding such needs, studies of cosmetic surgery for the women in their twenties and thirties have primarily focused on quantitative analysis of the features of cosmetic surgery, such as body image, attitudes toward plastic surgery, receptivity, and satisfaction. ${ }^{2,11,12}$ There have also been some qualitative studies that investigated the motivations, perceptions, and responses to their body in recipients, or potential recipients of cosmetic surgery. ${ }^{10,13-20}$ Practically, none of these studies, however, has examined the side effects of cosmetic surgery in-depth.

When studying a research topic with a minimal accumulation of relevant knowledge, a qualitative study would be appropriate in investigating the experiences within the natural context in order to acquire an overall and deeper understanding. In this sense, phenomenological studies enable researchers to better understand how the participants perceive the phenomenon in question, and how their perceptions influence their behaviors. ${ }^{21}$ In particular, the phenomenological method suggested by Colaizzi, ${ }^{22}$ which is based on the conceptualization that psychological experiences cannot be observed through eyes, but can be perceptually described, is characterized by describing the fundamental structure of a shared experience with a method in restating the experiences of each participant into a more general structure. In addition, this method has the advantage of eliminating any potential preconceptions of the researcher, since the redescribed experience is verified by the participant.
In this context, the present study attempted to understand, from the perspective of the participants, the fundamental structures of experiences of women in their twenties and thirties who have suffered from side effects of FPS, by taking a phenomenological approach in examining their lived experiences.

\section{Participants and methods Study population and analytical approach}

A descriptive phenomenological study was conducted to explore the subjective experiences of women in their twenties and thirties with plastic surgery side effects. Colaizzi's ${ }^{22}$ phenomenological method was used.

The participants underwent $1-4$ rounds of surgical aesthetic procedures (mean 2.3 rounds) and 0-14 rounds of nonsurgical aesthetic procedures (mean 4.3 rounds). Four participants underwent reoperation due to side effects. The three remaining participants visited a hospital with the intention of reoperation. In the present study, aesthetic procedures were investigated; 31 of the 32 types of aesthetic procedures described by the ISAPS ${ }^{1}$ (Surgical 19, Nonsurgical 13, excluding "breast reduction for men") and the side effects of FPS were defined as all inappropriate events that occurred as a result of FPS.

Data were collected from July to September 2015 via oneon-one in-depth interviews with the participants. Interviews were conducted in a quiet area that was agreed upon with the participants beforehand. Interviews began with small talk to help the participants feel comfortable, and the following open-ended question was used: "Could you freely tell me about your thoughts or experiences with side effects of your aesthetic procedures?" Some of the following specific questions were asked, depending on the course of the interview, including "What else happened?", "How did you feel?", and "How did you react?" We prompted each participant to discuss their stories as much as possible. When we felt that the experiences of the side effects of an aesthetic procedure were not fully stated, we reengaged in the interview, after engaging in more small talk. At the end of the interview, we added questions regarding the general characteristics of the participants, as well as the types of procedures they underwent. Each interview session lasted for 60-90 minutes and was continued until the investigator determined that data saturation was reached. Short notes were taken during the interview as necessary, and the investigator transcribed the recorded interviews verbatim.

Colaizzi's ${ }^{22}$ seven-stage process for data analysis was utilized. First, all of the descriptions provided by the subjects were read, in order to acquire a feeling for tone, 
and to facilitate understanding. Second, each transcription was examined for significant statements. Third, the meanings of the statements were analyzed and defined. Fourth, the above was repeated for each protocol, and information was organized and aggregated to formulate meaning into clusters of themes. Fifth, the results of everything described thus far were integrated into an exhaustive description of the investigated topic. Sixth, an effort was made to formulate the exhaustive description of the investigated phenomenon in as unequivocal a statement as possible, to assist in the identification of the fundamental structure of the description. Finally, the resulting statements were discussed with the research participants, in an effort to obtain final validation. To ensure rigor, we complied with the standards for true value, applicability, consistency, and neutrality, ${ }^{23}$ and performed bracketing and verification, which are emphasized by both phenomenology and Colaizzi. ${ }^{22}$

\section{Ethical approval}

All participants were informed of the study objective, procedures, and that they had the option to withdraw from the study at any time. Following this, we obtained written informed consent from all participants. The study was approved by the institutional review board of the Chonnam National University (IRB No 1040198-150618-HR-021-01).

\section{Results}

Data were collected from 16 interviews with 7 participants. Table 1 summarizes participant characteristics. Their significant statements were extracted, and these were clustered into 6 themes and 25 subthemes.

\section{Choosing FPS to gain a new self}

This theme is composed of two subthemes: "planned choice" and "accidental choice". An expectation for acquiring a better appearance or overcoming any appearance complex underlies both planned and unplanned (accidental) decisions.
The participants actively planned and decided to undergo FPS. Some received financial support from their family, while some paid the expenses themselves. Those who received financial support from their family underwent plastic surgery at an earlier period than those who paid the expenses by themselves and tended to neglect adequate preoperative research. The participants stated that in addition to overcoming their appearance complex, the factors, such as appearances preferred by men, appearance of youth, desire to become beautiful, and successful cases of friends or others, influenced their decision to undergo cosmetic surgery.

Looking at the before and after images [in magazines], I had a kind of thought that if this person could become this more pretty, I would become even prettier. So, I nagged my parents. [Participant 1]

Some participants decided to undergo a plastic surgery not because of complaints about their appearance or their desire to become beautiful, but because of the recommendation of a family member (primarily the mother). In addition, some participants just happened to make the decision at the clinic when they accompanied their friend after the college entrance exam.

My mom had a plastic surgery. She had her eyelids done years back, and it was successful, too. They were really nicely done. I think it was because my mom had a successful double eyelid surgery. She just grabbed my arm and took me to a plastic surgery clinic one day. [Participant 2]

\section{Facing an unintended self}

This theme is composed of three subthemes: "having physical scars", "suffering from psychological pain", and "having conflicts in interpersonal relationships".

The participants suffered from physical side effects following an FPS. The symptoms varied, and the period of onset differed, depending on the type of surgery undergone.

Table I General characteristics of participants

\begin{tabular}{|c|c|c|c|c|c|c|c|c|c|c|}
\hline \multirow[t]{2}{*}{ No } & \multirow[t]{2}{*}{ Age } & \multirow{2}{*}{$\begin{array}{l}\text { Education } \\
\text { level }\end{array}$} & \multirow{2}{*}{$\begin{array}{l}\text { Marital } \\
\text { status }\end{array}$} & \multirow[t]{2}{*}{ Occupation } & \multicolumn{2}{|c|}{ Experience of PS } & \multirow{2}{*}{$\begin{array}{l}\text { Age of } \\
\text { first PS } \\
\text { (year) }\end{array}$} & \multirow{2}{*}{$\begin{array}{l}\text { Sites of } \\
\text { side effects }\end{array}$} & \multirow{2}{*}{$\begin{array}{l}\text { Experience } \\
\text { of re-PS } \\
\text { (year) }\end{array}$} & \multirow{2}{*}{$\begin{array}{l}\text { Medical } \\
\text { counseling }\end{array}$} \\
\hline & & & & & $\begin{array}{l}\text { No of } \\
\text { surgical PS }\end{array}$ & $\begin{array}{l}\text { No of } \\
\text { nonsurgical PS }\end{array}$ & & & & \\
\hline I & 35 & $\mathrm{BA}$ & Married & Housewife & 3 & 14 & $15(1995)$ & Eyelids & 1996 & Yes \\
\hline 2 & 36 & $\mathrm{MA}$ & Single & Office worker & 2 & 0 & $21(2000)$ & Eyelids & 2011 & Yes \\
\hline 3 & 37 & DR student & Married & Business & 4 & 1 & $18(1996)$ & Nose, Eyelids & I999, 200| & Yes \\
\hline 4 & 35 & $\mathrm{BA}$ & Single & Office worker & 4 & 10 & $28(2008)$ & Jaw & 2011 & Yes \\
\hline 5 & 25 & $\mathrm{BA}$ & Single & Business & I & 0 & $18(2008)$ & Eyelids & None & Yes \\
\hline 6 & 33 & BA & Single & Office worker & 1 & 0 & $28(2010)$ & Eyelids & None & Yes \\
\hline 7 & 24 & MA student & Single & Full-time student & 1 & 5 & $15(2006)$ & Eyelids & None & Yes \\
\hline
\end{tabular}

Abbreviations: BA, bachelor; DR, doctoral; MA, master; PS, plastic surgery. 
Side effects of the most frequently performed double eyelid surgery included a clearly visible surgical scar, lagophthalmos, xeroma, asymmetry, and paresthesia. It was the wish of the participants to enhance their appearance naturally, as if no surgery had been performed, but instead, they were left with permanent, conspicuous scars at the surgical site. After undergoing an FPS, the participants suffered from fear, shame, distress, depression, being upset, anger, and a victim mentality. The participants experienced conflicts with the family members who recommended surgery to them, as well as conflicts between other family members. Furthermore, they were faced with ridicule and misunderstanding by their friends and teachers at school and developed mistrust and frustration toward medical staff and medical facilities. They were emotionally hurt by callus jokes and passing comments. They also stated that the information that they had received plastic surgery, which they wished to keep hidden, was disclosed by the inconsiderate comments of others. They were embarrassed and baffled by strangers on the streets asking them about their plastic surgery, and even plastic surgeons, with whom they met privately, asking about where they have received the surgery.

\section{Trying to accept a changed self}

This theme is composed of four subthemes: "abandoning expectations", "not wanting to change current status", "trying to forget", and "attempting to accept oneself". These represent the early period of adaptation to the side effects by participants.

The participants waited, with hope, for a period set by themselves, or by their doctors ( 6 months to 1 year), after which they fell into despair. Participants who underwent a surgery at a too young age sometimes displayed ambivalent emotions, where they regretted the choice of cosmetic surgery without more research but were unregretful about the successful surgeries. Although they suffered from side effects, they said that they did not want to return to the state of appearance prior to the surgery. Although the participants suffered from side effects of a cosmetic surgery, they stated that they forgot the surgery-related memories while they kept themselves busy with life. The participants showed an attitude of acceptance toward the reality of their appearance, by adapting it to the situation.

Even the celebrities have folding and dragging of the eyelids when they age. So I try to tell myself things like "I look okay right now," and "It seems okay if I don't pay attention to it." I also became kind of numb as I became older. [Participant 5]

\section{Making efforts to overcome the situation}

This theme is composed of five subthemes: "comforting by comparison of oneself to others that have suffered serious side effects", "trying to compensate for side effects in other ways besides plastic surgery", "trying to balance side effects with plastic surgeries on other parts of body", "contemplating resurgery", and "choosing resurgery with the hope of a better result". This theme represents a series of experiences that the participants cope with in order to overcome the side effects of FPS.

The participants comforted themselves by thinking that their side effects were mild when compared with the severe side effects of extreme cases shown on television or compared with cases of people that they knew. The participants stated that they tried to polish their appearance and to complement their side effects with other nonsurgical methods, such as skin massage, eyelash extensions, makeup, semipermanent makeup, and smiling practice. The participants underwent additional plastic surgery in other parts of the body to achieve an aesthetic balance between body parts. Some underwent additional surgical procedures on the eyes, nose, and philtrum, and some received fraxel laser, Intense Pulsed Light (IPL) procedures, and Botox injections in the facial area and/or laser epilation in the armpits. They pointed to convenient access as the strength of cosmetic surgery, but also showed concerns for thinning of skin, sensitivity, and paresthesia that could occur with repeated procedures.

Well, my nose was too low and small compared to the big eyes. It seemed to make my eyes more conspicuous. People began to stop talking about my eyes after my nose job. [Participant 1]

The participants stated that they hesitated to undergo reoperation because of worries that things might get worse, as well as financial reasons. After some time of coping with the side effects from a cosmetic surgery, some participants underwent reoperation at the same or different hospital, in the hopes of improving the symptoms. The reoperation expenses were paid either by the participant or by the hospital:

[After the first plastic surgery] they told me that my lower chin had to be pushed in further. It just took me by surprise because I hadn't even recovered yet. But I mean, I can't not do the surgery [...]. It was kind of a mistake (on the part of the hospital). So, they did this, this autologous fat injection into my forehead for free. [Participant 4]

\section{Coming to know a new world}

This theme is composed of five subthemes: "realizing the limitations of plastic surgery", "understanding of the family 
member(s) who recommended plastic surgery", "concern about someone else's plastic surgery", "worrying about the social trend", and "having a critical perspective". The participants reflected on their experiences of the side effects and discovered meaning in the experiences.

The participants came to realize that the beauty that they direly sought to achieve with FPS is fragmentary and transient. A participant who had a successful reoperation said that she understood why her mom recommended her to receive FPS. While talking about their life stories related to the side effects of plastic surgery, the participants said that they wished other people were aware of the side effects and were more prudent in choosing to undergo plastic surgery. Furthermore, they suggested going on a diet or trying makeup before choosing plastic surgery.

The participants mentioned that plastic surgery has made everyone look similar and expressed a concern for both unscreened plastic surgery and ads bombarding the city. They asked people to be aware of these and to do thorough research before deciding to undergo surgery. They referred to cases in the USA and China, where individuality was valued, and little attention was paid to outward appearances, and stated that Korea virtually stood at the opposite pole. In Korea, they claimed, it is easy to encounter people who have had aesthetic surgeries, while it is difficult to remember the individual traits of people, primarily due to television and the social climate.

The participants criticized that the "plastic beauties" and highly contrasted pictures of before and after that were plastered on the walls of subway stations and are continuously exposed through magazines and television shows beguiled people, and that these commercial exploitations increasingly standardized the definition of beauty. Furthermore, the participants also demonstrated critical attitudes toward some members of medical staff during consultations and their strategies of recruiting patients.

There are a lot of discounts and promotions when we take our friends when we visit the plastic surgery clinic, so we talk about going together a lot [...]. It kind of seems like $1+1$ promotions in markets. [Participant 7]

\section{Pursuing a new lifestyle}

This theme is composed of six subthemes: "getting over the memory of side effects", "feeling satisfied with the current appearance", "not seeking any more plastic surgeries", "not hiding the experience of plastic surgery", "pursuing satisfaction in different ways", and "living a more authentic life". The participants wished to pursue a new, more mature life, with the insights that they gained by coping with and overcoming the side effects received.

Most participants claimed to have an optimistic personality and were not reluctant to talk about the side effects of plastic surgery. However, one participant who did not achieve satisfactory results and still had side effects, even after a reoperation, stated that she decided to participate in the interview to overcome her situation. Some participants only contemplated reoperation and eventually decided not to undergo reoperation, saying that they were satisfied with how they looked. Furthermore, even if they were not satisfied with their looks, they seemed like they had given up and expressed familiarity with their looks. Participants who underwent reoperation were satisfied with their current looks.

All participants stated that they would not seek plastic surgery anymore. However, they left open the possibility of undergoing aesthetic procedures, depending on the circumstances (when they aged). The participants stated that they did not hide their history of plastic surgery when they were asked about it. However, they said that they did not answer immediately when they were asked by their romantic partners.

Wouldn't it have to do with social climate? Before, everyone seemed to hide it, but now they are open about it because it seems like everyone does it. [Participant 5]

The participants addressed their appearance overall with nonsurgical methods, such as clothing, accessories, makeup, and tattoos, and were satisfied with their current lives.

I care about everything from head to toe, not only clothing, but even a tiny accessory. I take care of my looks this much because I don't want to get anymore plastic surgeries.

[Participant 3]

All participants were involved in one or more jobs, such as working and studying, and adopted a future-oriented lifestyle.

\section{Discussion}

At a point where a quantitative increase of aesthetic surgeries has also increased subsequent cases of side effects, the present study performed in-depth interviews and described the life experiences of Korean women in their twenties to thirties who have suffered from the side effects of FPS. The current study is unlike existing studies that have focused primarily on investigating both the aesthetic procedure-related factors and side effects together. This study found 6 themes and 25 subthemes, which comprise the fundamental structures of the experiences. These findings indicate that Korean 
women in their twenties to thirties, who have experienced side effects of FPS, tried to accept and overcome their unexpected changed realities. While their understandings of others and society were broadened, they strived to live a more conscientious life. Detailed discussions about the results are as follows.

The first theme was "choosing FPS to gain a new self". Some of the participants decided to undergo the FPS based on active preplanning in order to overcome their appearance complex or to achieve a more desirable appearance. Meanwhile, some chose plastic surgeries without much planning, based on the recommendations of their mothers or friends. These results are in line with other studies that suggest that public media or social factors motivate individuals to decide on aesthetic procedures. ${ }^{2,11,14}$ In fact, many women who undergo plastic surgeries are doing so to heighten their confidence in relationships with others, or to increase their competitiveness in marriage or employment. As such, those who succeed in a makeover through plastic surgeries interact in society with an increased competitiveness and tend to receive more friendly feedback. ${ }^{10,20}$ However, this is only the case for those who have obtained successful and satisfactory plastic surgery outcomes. Follow-up studies on such internal and external factors would be able to delay the decisions of individuals to undergo surgery, as well as the onset of side effects.

The second theme was "facing an unintended self". The participants suffered various physical, psychological, and social side effects, without thinking about the possibility that they could be the victims of side effects of a cosmetic surgery. ${ }^{8,9}$ Gimlin ${ }^{16}$ suggested that even women who have had a successful plastic surgery could potentially be faced with responsibility and criticism for being fake, and Boulton and Malacrida ${ }^{15}$ have suggested that women who have undergone cosmetic surgery could be disappointed with outcomes that fell short of their expectations. Furthermore, such unsatisfactory outcomes raise the disputes of responsibility. For instance, if a patient files a complaint about inflammation that developed during the cosmetic surgery, in most cases, the complaint is settled by the hospital offering reoperation, refund, or reimbursement for medical treatment expenses, rather than by reaching an agreement as to the cause and agent of responsibility. ${ }^{17}$ In addition, another study reported that most surgeons either hired a conflict resolver or tried not to take aggressive actions in response to the conflicts caused by the side effects. ${ }^{12}$ The participants in our study did not state life-threatening side effects, but their experiences of the side effects would not only undermine their self-esteem, but also considerably influence their attitudes toward medical staff and facilities, as well as ultimately health and welfare policies and social trends.

The third theme was "trying to accept a changed self". The participants waited in hope that things would get better over time, but as they faced the fact that the changes would not be reversed, they eventually gave up. In addition, they tried to comfort themselves by thinking that their looks were fine and also tried to forget about the bad experience. These results are partially in line with a study by Leem, ${ }^{17}$ which reported that there was a gap between people's expectation of immediately becoming more beautiful after a plastic surgery and their physical reality requiring time for recovery and healing, and that some people were still dissatisfied with their looks after undergoing changes through plastic surgery. In addition, our results are also partially similar to the reports suggested by Park and Lee, ${ }^{19}$ where patients who underwent plastic surgery miss their old looks, but those who had successful outcomes regain their confidence, engaging in repeated display of their looks by frequently looking in the mirror or wearing makeup. This shows that the participants accepted the reality of the side effects that accompanied their cosmetic surgery but are struggling to move on with a focus on the positive aspects.

The fourth theme was "making efforts to overcome the situation". The participants comforted themselves by comparing their cases with those who have experienced worse side effects, tried to compensate for side effects through other nonsurgical methods, and strived to achieve a balanced look by undergoing surgery on another part of the body. This partially supports previous studies, where female participants who underwent FPS stressed that they were different from extreme cases of plastic surgery addiction, ${ }^{18}$ and where participants with experience of cosmetic surgery planned for additional surgeries in the future. ${ }^{13}$ In addition, the results of the current study are also partially similar to studies that showed participants who have undergone plastic surgery in an effort to feel a similarity with others who have had the same surgery, and that these individuals also showed an interest in additional surgery, depending on the outcomes of those who underwent surgery on another part of the body. ${ }^{19}$ Furthermore, the fact that many participants left open the possibility of receiving cosmetic procedures, such as Botox injections, in the future reflects the current social trend of plastic surgery as commonplace, primarily due to the growing popularity of cosmetic procedures that produce immediate body changes through drug injections. ${ }^{25}$

The fifth theme was "coming to know a new world". The participants realized the limitations of plastic surgery 
through their experiences of the side effects of FPS. These results are in a similar context to those reported by Leem, ${ }^{17}$ who discussed Korean women on the streets with very similar faces that were produced based on a uniform medical standard, Korean women who set their beauty standards on Western actresses, and women of other Asian countries, who set their beauty standard on Korean women. As more people begin to undergo repeated procedures to attain the unattainable "perfect" body, terms such as "scalpel slaves"26 and "surgery junkies" 27 have been used for some time. The participants stated that they were undoubtedly exposed to cosmetic procedures at a young age through television or magazines. They expressed regret, saying that it would have been better if they knew more about plastic surgery then, or if they had encountered plastic surgery at an older age. Such sentiments could easily be inferred, considering the fact that the number of cases of physical deformation caused by cosmetic surgeries at a young age is rapidly increasing, ${ }^{5,14}$ and that the public media and past plastic surgery experiences have significant effects on the cosmetic surgery intention of individuals. ${ }^{2,11}$ In light of these findings, developing and instituting education regarding plastic surgery in school health classes would help adolescents to establish an appropriate body image and could prevent the spread of a trend that encourages early plastic surgery. An early awareness campaign on the severity of FPS side effects can also be an alternative.

The final theme was "pursuing a new lifestyle". The participants either have overcome, or wish to overcome, their memories concerning the side effects of plastic surgery. Regardless of whether they have undergone reoperation or not, the participants claimed that they were satisfied with their current appearance and did not wish to seek further cosmetic surgery. They do not necessarily hide their history of plastic surgery when asked, but do not disclose it themselves if not asked. Particularly, they avoid answering immediately when asked by their romantic partners. They seek satisfaction through methods other than plastic surgery and commit to their lives with a future-oriented attitude. Although it is difficult to conclude that all participants have transcended their experiences with the side effects of cosmetic surgery, all participants stated that they would be more prudent in deciding to undergo cosmetic procedures in the future. The current results cannot be compared directly to any other study, as there is no other study that has examined the experiences of women who have overcome the side effects of plastic surgery. However, the current results can be compared to those of a study that has examined the experiences associated with overcoming other diseases that are related to the body images of women. For instance, a study that investigated the positive coping methods experienced by women who underwent thyroidectomy as they overcome their anxiety, ${ }^{28}$ and a study suggesting that breast cancer survivors reflect on themselves and pursue a new life ${ }^{29}$ are similar. These findings hint that the participants of our study ultimately mature and pursue a future-oriented life through a series of experiences that they endure as they overcome the side effects of plastic surgery. These results present a message of hope and optimism for patients who are suffering from similar issues, while serving as a message of warning to those who choose to undergo cosmetic procedures without sufficient research or consideration.

One of the limitations of this study is that it did not deal with the unconscious motives of women seeking FPS. The lives of the participants who have suffered the unfavorable side effects of cosmetic surgery and overcome them may have been influenced by unconscious factors. In addition, the need and desire for cosmetic surgery of the individuals may be different from medical judgement. ${ }^{24,30} \mathrm{We}$ propose a follow-up study that examines this more closely.

This study describes the journey of women suffering from the side effects of FPS as they strive to overcome their negative experiences. The findings of this study could have been influenced by the unique sociocultural climate of the Korean society. Thus, in order to delay the age at which women decide on plastic surgeries, and minimize side effects, it is important to form a social consensus, and to initiate discussions on developing relevant health policy measures.

\section{Conclusion}

The objective of the current study was to acquire a deeper understanding of the essential structures of the experiences of women in their twenties to thirties, who have encountered side effects of FPS. The findings of this study can serve as basic data for devising nursing strategies and systematic health policies that would be helpful for patients suffering from the side effects of cosmetic surgery, as well as for health professionals providing care for these individuals. This study will also contribute to promoting the awareness of the side effects that may accompany aesthetic surgeries and fostering a social climate in which people display critical views of the craze for plastic surgery. Furthermore, the findings of this study could establish the foundation upon which future studies will be able to examine the provision of whole-person nursing in response to individual needs, in addition to the side effects and reoperations of cosmetic surgeries. 


\section{Acknowledgments}

This work was supported by the National Research Foundation of Korea (NRF) grant funded by the Korea government (MSIT; Ministry of Science and ICT) (No. NRF2017R1C1B5016043).

\section{Disclosure}

This manuscript is based on a part of Kim YA's doctoral dissertation from Chonnam National University. The authors report no other conflicts of interest in this work.

\section{References}

1. International Society of Aesthetic Plastic Surgery (ISAPS). ISAPS International Survey On Aesthetic/Cosmetic Procedures Performed in 2011. ISAPS; 2011. Available from: https://www.isaps.org/wp-content/ uploads/2017/10/ISAPS-Results-Procedures-2011-1.pdf. Accessed May 31, 2018.

2. Kim YA, Chung HI. Factors affecting plastic surgery addiction tendency among undergraduate women. J Digit Convergen. 2014; 12(12):621-631.

3. Seoul Metropolitan Government. 2015 Seoul Survey Report. Seoul: Seoul Metropolitan Government; 2015.

4. Bordo S. Unbearable Weight: Feminism, Western Culture and the Body. Berkely, CA, USA: University of California Press; 1993.

5. McGrath M, Mukerji S. Plastic surgery and the teenage patient. J Pediatr Adolesc Gynecol. 2000;13(3):105-118.

6. Shilling C. The Body and Social Theory. 2nd ed. London: Sage; 2003.

7. Korea Consumer Agency. Asymmetry Complaints on Side Effects of Plastic Surgery. Chungcheongbuk-do: Korea Consumer Agency; 2015.

8. National Evidence-based Healthcare Collaborating Agency. Determine the Status of Cosmetic Plastic Procedure and the Development of Information Booklet for the Users. Seoul: National Evidence-based Healthcare Collaborating Agency; 2014.

9. US. Department of Health and Human Services. Body Image: Cosmetic Surgery. WA, USA: Office on Women's Health; 2009.

10. Woo KJ. The Relation Between Women's Obsession Over Appearance and the Cosmetic Surgery Industry in the Contemporary Korea [dissertation]. Seoul: Yonsei University; 2002.

11. Markey CN, Markey PM. A correlational and experimental examination of reality television viewing and interest in cosmetic surgery. Body Image. 2010;7(2):165-171.

12. Nah YK, Tae HW, Roh JH, et al. Teen girls' daily lives and the "beauty industry" encouraging "lookism". J Korean Womens Stud. 2009;25(4): 73-108.
13. Adams J. Motivational narratives and assessments of the body after cosmetic surgery. Qual Health Res. 2010;20(6):755-767.

14. Dorneles de Andrade D. On norms and bodies: findings from field research on cosmetic surgery in Rio de Janeiro, Brazil. Reprod Health Matters. 2010;18(35):74-83.

15. Boulton TN, Malacrida C. Women and cosmetic breast surgery: weighing the medical, social, and lifestyle risks. Qual Health Res. 2015;22(4): 511-523.

16. Gimlin D. Cosmetic surgery: beauty as commodity. Qual Sociol. 2000;23(1):77-98.

17. Leem SY. A Network of Things, Bodies, and Knowledges in Plastic Surgery Practices [Dissertation]. Seoul: Seoul National University; 2012.

18. Leve M, Rubin L, Pusic A. Cosmetic surgery and neoliberalisms: managing risk and responsibility. Femin Psychol. 2012;22(1):122-141.

19. Park UH, Lee JS. A study on hospital experiences of plastic surgery patients. J Korean Acad Psychiatr Mental Health Nurs. 2000;9(1): 64-78.

20. Solvi AS, Foss K, von Soest T, Roald HE, Skolleborg KC, Holte A. Motivational factors and psychological processes in cosmetic breast augmentation surgery. J Plast Reconstr Aesthet Surg. 2010;63(4): 673-680.

21. Maxwell J. Qualitative Research Design: An Interactive Approach. Thousand Oaks, CA, USA: Sage; 1996.

22. Colaizzi P. Psychological research as the phenomenologist views it. In: Valle RS, King M, editors. Existential Phenomenological Alternatives for Psychology. New York, NY, USA: Oxford University Press; 1978: $48-71$.

23. Lincoln Y, Guba E. Naturalistic Inquiry. Beverly Hills, CA, USA: Sage; 1985.

24. Goldwyn RM. The consultant and the unfavorable result. In: Goldwyn RM, editor. The Unfavorable Result in Plastic Surgery. Boston, MA, USA: Little, Brown and Company; 1972:1-4.

25. Elliott A. Drastic plastic and the global electronic economy. Society. 2009;46(4):357-362.

26. Conant J, Gordon J, Donovan J. Scalpel slaves just can't quit. Newsweek. 1988:58-59.

27. Pitts-Taylor V. Surgery Junkies: Wellness and Pathology in Cosmetic Culture. NJ, USA: Rutgers University Press; 2007.

28. Lee KJ, Chang SO, Jung KY. Experiences with a low-iodine diet: a qualitative study of patients with thyroid cancer receiving radioactive iodine therapy. Eur J Oncol Nurs. 2016;23:43-50.

29. Documet PI, Trauth J, Key M, Flatt J, Jernigan J. Breast cancer survivors' perception of survivorship. Oncol Nurs Forum. 2012;39(3):309-315.

30. Belfer ML. Beyond surgery: treating the whole person. J Oral Maxillofac Surg. 2015;73(12 Suppl):S17-S19.
International Journal of Women's Health

\section{Publish your work in this journal}

The International Journal of Women's Health is an international, peerreviewed open-access journal publishing original research, reports, editorials, reviews and commentaries on all aspects of women's healthcare including gynecology, obstetrics, and breast cancer. The manuscript management system is completely online and includes
Dovepress

a very quick and fair peer-review system, which is all easy to use. Visit http://www.dovepress.com/testimonials.php to read real quotes from published authors. 